\title{
The Impact of the Ageing Process on Taiwanese Elderly
}

\author{
Chen-Yuan Hsu* \\ Department of Nursing, Da-Yeh University, Taiwan
}

Received: 阱 May 29, 2018; Published: 阱 June 06, 2018

*Corresponding author: Chen-Yuan Hsu, Department of Nursing, Da-Yeh University, Taiwan

\begin{abstract}
Taiwanese elderly who has increased rapidly, the purpose of this review to understand the impact of the ageing process on those people. Expecting by the review provides the references for nursing staff to have a knowledge and attention for those people and resulted to improve the well-being life for elderly.
\end{abstract}

\section{Introduction}

Ageing brings with it a number of influences on health and can result in increased frailty and diagnoses of chronic disease that can influence mental health and development of disabilities [1-4].

The majority of people older than 65 years of age are estimated to have at least one chronic physical or psychological illness. The major diseases of older people include diabetes, arthritis, cancer, cardiovascular disease, musculoskeletal problems, incontinence, osteoarthritis, sleep disturbances, chronic pain and falls [1,2,48]. These physical problems can result in the older population in Taiwan experiencing lower life satisfaction, poor health, and problems with mobility [1,7]. Furthermore, ageing can result in psychological problems, such as mental health deterioration, dependency as a result of illness, dementia, sensory impairments and depression [2,6]. This clearly indicates that older people suffer from a wide range of illnesses and health-related problems and may also have to deal with reduced ability to maintain their daily activities.

The impact of ageing on health becomes more complex when there is disability or frailty [6]. These health problems of the older population in Taiwan and various social-economic changes have resulted in long term care (LTC) facilities becoming a care option for older people [8]. This is particularly the case when older people become dependent on assistive devices or others for care and help with their daily lives, performing activities of daily living (ADL) such as bathing, dressing, eating, transferring from a bed to a chair, and toileting [9].

Nevertheless, although most "aged society" countries are faced with the task of establishing LTC systems, there is still a lack of understanding of how such care systems affect the quality of life (QOL) for older people [10], particularly those who are limited to using a wheelchair for their mobility and daily activities [11,12]. Therefore, applying well-being life on the Taiwanese elderly should be paid a comprehensive attention.

\section{Conclusion}

This contributes to a relatively knowledge and offers an attention of emphasizing the well-being life of Taiwanese elderly. The daily activities related program as a psychological health maintenance activity and/or social activity for Taiwanese elderly should be supported. This will be a valuable option for improving the well-being life of elderly.

\section{References}

1. Chiou AF, Lin HY, Huang HY (2009) Disability and pain management methods of Taiwanese arthritic older patients. Journal of Clinical Nursing 18(15): 2206-2216.

2. Lin PC, Wang HH, Huang HT (2007) Depressive symptoms among older residents at nursing homes in Taiwan. Journal of Clinical Nursing 16(9): 1719-1725.

3. Lin MR, Wolf SL, Hwang HF, Gong SY, Chen CY (2007) A randomized, controlled trial of fall prevention programs and quality of life in older fallers. Journal of the American Geriatrics Society 55(4): 499-506.

4. Tsai YF, Wong TK, Ku YC (2008) Self-care management of sleep disturbances and risk factors for poor sleep among older residents of Taiwanese nursing homes. Journal of Clinical Nursing 17(9): 1219-1226.

5. Bowling A, Seetai S, Morris R, Ebrahim S (2007) Quality of life among older people with poor functioning. The influence of perceived control over life. Age And Ageing 36(3): 310-315.

6. Watson R (2008) Research into ageing and older people. Journal of Nursing Management 16(2): 99-104. 
7. Yu HY, Tang FI, Kuo BI, Yu S (2006) Prevalence, interference, and risk factors for chronic pain among Taiwanese community older people. Pain Management Nursing: Official Journal of The American Society of Pain Management Nurses 7(1): 2-11.

8. Wu SC, White A, Cash K, Foster S (2009) Nursing home care for older people in Taiwan: A process of forced choice. Journal of Clinical Nursing 18(14): 1986-1993.

9. Luleci E, Hey W, Subasi F (2008) Assessing selected quality of life factors of nursing home residents in Turkey. Archives of Gerontology and Geriatrics 46(1): 57-66.
10. Kim SH (2009) Older people's expectations regarding ageing, healthpromoting behaviour and health status. Journal of Advanced Nursing 65(1): 84-91.

11. Hsu CY, Moyle W, Cooke M, Jones C (2016) Seated Tai Chi versus usual activities in older people using wheelchairs: A randomized controlled trial. Complement Ther Med 24: 1-6.

12. Hsu CY, Moyle W, Cooke M, Jones C (2016) Seated T'ai Chi in Older Taiwanese People Using Wheelchairs: A Randomized Controlled Trial Investigating Mood States and Self-Efficacy. [Randomized Controlled Trial]. J Altern Complement Med 22(12): 990-996.

\section{(c)}

This work is licensed under Creative Commons Attribution 4.0 License

To Submit Your Article Click Here:

Submit Article

DOI: $10.32474 /$ LOJNHC.2018.01.000113

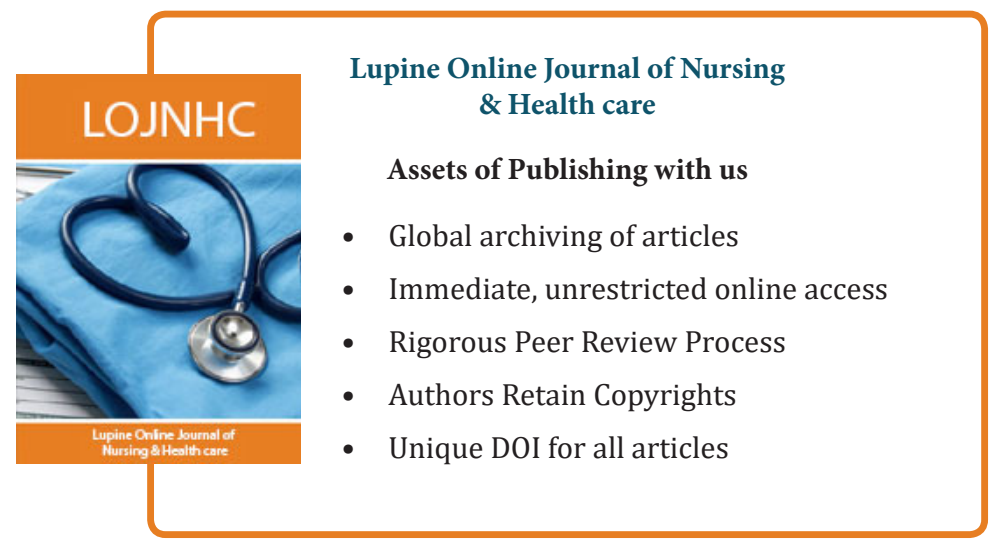

